\title{
A virtualização do ensino superior de ciências contábeis: implementação de atividades complementares culturais avaliadas por habilidades
}

\author{
Virtualization of higher education of accounting sciences: implementation of complemetary cultural \\ acrivitiees assesses by competences \\ Virtualización de la enseñanza superior de ciencias contables: implementación de atividades comple- \\ mentarias culturales evaluadas por competencias
}

DOI: https://doi.org/10.21803/pensam.v12i22.246

Maria das Graças Freitas dos Santos https://orcid.org/0000-0002-7219-2801

Nilton Rogério Marcondes https://orcid.org/0000-0002-5459-5367

\section{¿Cómo citar este artículo?}

DosSantos, M. \& Marcondes, M. (2019). Virtualização do ensino superior de ciências contábeis: implementação de atividades complementares culturais avaliadas por competências. Pensamiento Americano, 12(23), 47-56

DOI: https://doi.org/10.21803/pensam.v12i22.246

\begin{abstract}
Resumo
Este artigo apresenta uma proposta para a implementação de Atividades Complementares Culturais (ACC) avaliadas por habilidades no curso de Bacharelado em Ciências Contáveis, oferecido na modalidade virtual. A temática é relevante porque sugere a necessidade de direcionar e alinhar a virtualização do bacharelado, a fim de assegurar a educação inclusiva, equitativa e de qualidade, bem como promover as oportunidades de aprendizagem com base nas orientações do Ministério da Educação e com o enfoque no objetivo 4 da Organização das Nações Unidas no Brasil, que visa aumentar o número de jovens e adultos possuidores de competências relevantes para o trabalho decente e/ou ao empreendedorismo. Na questão Problema da Pesquisa, busca-se compreender: qual recurso pode ser utilizado para o planejamento das atividades complementares, ofertadas em ambiente virtual, de modo que as propostas de aprendizagem possam estar bem alinhadas para proporcionar conhecimentos, desenvolver habilidades e incentivar atitudes compatíveis com as competências necessárias para a formação dos alunos. Os procedimentos metodológicos consistem numa abordagem qualitativa exploratória, pois foi efetuado o estudo de caso em uma universidade particular localizada na Baixada Santista, São Paulo, Brasil. Neste sentido, foram elaborados objetos de aprendizagem direcionados para atender as competências listadas na matriz de referência. Após a elaboração das atividades, foi possível verificar que os objetos de aprendizagem corroboram o oferecimento do conhecimento, o desenvolvimento das habilidades e o incentivo das atitudes. As considerações finais sugerem a necessidade de uma nova abordagem das atividades complementares, porque podem transcorrer o estabelecido na legislação vigente.
\end{abstract}

Palavras-chave: Atividades complementares. Habilidades. Virtualização. Bacharelado em Ciências Contáveis. Matriz de referência.

\begin{abstract}
This article presents a proposal for the implementation of Cultural Complementary Activities (CCA) evaluated by competencies in the Bachelor of Accounting Sciences course, offered in the virtual modality. The theme is relevant because it suggests the need to direct and align the virtualization of high school in order to ensure inclusive, equitable and quality education, as well as promote learning opportunities based on the orientations of the Ministry of Education and with the focus on the objective development 4 of the United Nations Organization in Brazil, which seeks to increase the number of youth and adults possessing relevant skills for decent work and/or entrepreneurship. In the issue of the research problem, we seek to understand: what resource can be used for the planning of complementary activities, offered in a virtual environment, so that learning proposals can be well aligned to provide knowledge, develop skills and encourage attitudes compatible with the skills necessary for the training of students. The methodological procedures consist of a qualitative explo-
\end{abstract}

\footnotetext{
*Projeto Criare: Implementação de Certificação Profissional por Competências
} 
ratory approach; a case study was carried out in a particular university, located in the Baixada Santista, São Paulo, Brazil. In this sense, learning objects designed to meet the competencies listed in the reference matrix were developed. After the development of the activities, it was possible to verify that the learning objects corroborate the offer of knowledge, development of skills and incentive of attitudes. The final considerations suggest the need for a new approach to complementary activities because what is established in current legislation may take place.

Keywords: Complementary activities. Skills. Virtualization Bachelor of Accounting Sciences. Reference Matrix.

\section{Resumen}

Este artículo presenta una propuesta para la implementación de Actividades Complementarias Culturales (ACC) evaluadas por competencias en el curso de Licenciatura en Ciencias Contables, ofrecido en la modalidad virtual. La temática es relevante porque sugiere la necesidad de dirigir y alinear la virtualización del bachillerato a fin de asegurar la educación inclusiva, equitativa y de calidad, así como promover las oportunidades de aprendizaje con base en las orientaciones del Ministerio de Educación y con el enfoque en el desarrollo objetivo 4 de la Organización de las Naciones Unidas en Brasil, que busca aumentar el número de jóvenes y adultos poseedores de competencias relevantes para el trabajo decente y / o el espíritu empresarial. En la cuestión Problema de la investigación, se busca comprender: qué recurso puede ser utilizado para la planificación de las actividades complementarias, ofrecidas en ambiente virtual, de modo que las propuestas de aprendizaje puedan estar bien alineadas para proporcionar conocimientos, desarrollar habilidades e incentivar actitudes compatibles con las competencias necesarias para la formación de los alumnos. Los procedimientos metodológicos consisten en un abordaje cualitativo exploratorio, pues se efectuó un estudio de caso en una universidad particular, ubicada en la Baixada Santista, São Paulo, Brasil. En este sentido, se elaboraron objetos de aprendizaje dirigidos para atender las competencias listadas en la matriz de referencia. Después de la elaboración de las actividades, fue posible verificar que los objetos de aprendizaje corroboran el of recimiento del conocimiento, desarrollo de las habilidades e incentivo de las actitudes. Las consideraciones finales sugieren la necesidad de un nuevo enfoque de las actividades complementarias, porque puede transcurrir lo establecido en la legislación vigente.

Palabras clave: Actividades complementarias. Habilidades. La virtualización. Licenciatura Ciencias Contables. Matriz de referencia.

\section{Perfil}

Professora e mediadora em cursos oferecidos na modalidade virtual contemplando as áreas de conhecimento específico da administração e das ciências contábeis, pedagógica, comunicacional, tecnológica e gerencial, tendo em vista a aprendizagem significativa dos discentes, bem como a gestão de projetos com enfoque à melhoria contínua, no desenvolvimento de boas práticas, a partir de princípios éticos. Mestranda em Ecologia Humana - Linha de Pesquisa Economia Ecológica (2017), Especialista em Planejamento, Implementação e Gestão da Educação a Distância pela Universidade Federal Fluminense do Rio de Janeiro (2015), Bacharel em Ciências Contábeis pela Universidade Metropolitana de Santos (2012).

\section{Perfil}

Graduado em Ciências Contábeis pelo Instituto de Ensino Santo André (1993) Mestrado em Administração pela Universidade Metodista de São Paulo (2003), pós-graduação em contabilidade e finanças pelo Instituto de Ensino de Santo André, e atualmente é professor da Universidade Santa Cecilia (Graduação e Pós-Graduação), coordenador dos cursos tecnólogos em EaD na Universidade Santa Cecilia (UNISANTA), foi coordenador do curso de bacharelado em Ciências Contábeis no ensino a distância da Universidades Metropolitana de Santos - UNIMES VIRTUAL.

\section{Maria das Graças Freitas dos Santos}

Especialista em Planejamento, Implementação e Gestão da Educação

Nilton Rogério Marcondes Master of Business Administration de la Universidad Metodista de São Paulo 


\section{Introducción}

O surgimento de inovações tecnológicas no último meio século teve um enorme impacto nas possibilidades de aprendizagem, especialmente a convergência entre duas práticas inovadoras, como o ensino híbrido (blended learning), ou seja, uma forma de aprendizagem combinada entre o que é melhor do presencial e o que é que melhor do virtual, e a ludificação de gamificação Toukoumidis, Rodriguéz \& Rodriguéz (2018). A virtualidade de uma situação sociocultural complexa, onde contém diversos atores, cada um deles interagem com intenções e interpretações com a sua visão de mundo, pois envolve pessoas diferentes com competências, conhecimentos, habilidades e atitudes distintas. Esse fenômeno ocorre em todas as áreas abrangendo inclusive os processos de ensino-aprendizagem Noveli \& Albertin (2017).

Dentre esses processos, observa-se a virtualização do ensino superior no Brasil, fato observado pelo aumento de $66 \%$ das matrículas na modalidade à distância, no período de 2009 a 2015. Em 2017, 38,1\% das matrículas ocorrem na região sudeste, $20,8 \%$ na região sul, $18,7 \%$ na região nordeste, 12,5\% na região norte e 9,9\% na região centro-oeste (Semesp, 2017).

Em 2015, Ciências Contábeis ficou na quarta posição entre os cursos mais procurados em instituições de ensino superior particular: foram efetuadas 91.321 matrículas, sendo que 47.202 ingressaram e 12.179 concluíram. O estado de São Paulo possui cerca de mil polos de educação à distância: ele atingiu 264.786 matrículas em cursos virtuais. No entanto, na Baixada Santista, Ciências Contábeis ocupa a quinta posição na rede privada, porque foram realizadas 12.366 matrículas, ingressaram 6.570 e 1.668 alunos concluíram (Semesp, 2017).

As Atividades Complementares (AC) com- põem a matriz curricular do curso, com o objetivo de atender as Diretrizes Curriculares Nacionais para o curso de Ciências Contábeis e têm aprovação do Conselho Nacional de Educação - Câmara Nacional de Ensino Superior.

De acordo com o artigo $8^{\circ}$ da Resolução $n^{\circ}$ 10, de 16 de dezembro de 2004, as Atividades Complementares são componentes curriculares que possibilitam o reconhecimento, por avaliação, de habilidades, conhecimentos e competências do aluno, inclusive adquiridas fora do ambiente escolar, abrangendo a prática de estudos e atividades independentes, transversais, opcionais, de interdisciplinaridade, especialmente nas relações com o mundo do trabalho e com as ações de extensão junto à comunidade Inep (2017).

Assim, por ser um curso novo para a instituição, no início do primeiro semestre de 2018 o componente curricular foi oferecido aos alunos como forma de ampliação das ações formais que visem à melhoria da qualidade de vida e ao desenvolvimento pessoal, profissional, social, emocional e intelectual dos discentes. Para isso, todos os discentes regularmente matriculados no $4^{\circ}$ semestre do curso realizaram, porque as atividades complementares são requisitos obrigatórios no cumprimento da matriz curricular do $4^{\circ}$ aos $7^{\circ}$ semestres letivos.

As atividades complementares consistem na participação em eventos internos e externos à instituição de ensino superior, tais como: seminários, palestras, semanas acadêmicas, congressos, conferências, atividades culturais, atividades de iniciação científica, monitoria e a integralização de cursos de extensão, atualização acadêmica ou profissional.

O discente pode cumprir as atividades complementares de três maneiras: presencial, em sua cidade ou região, com a comprovação 
da participação por envio de documentos no Ambiente Virtual de Aprendizagem; à distância, realizando as atividades propostas no Ambiente Virtual de Aprendizagem ou híbrido, uma parte presencial e outra virtual. Para atingir a carga horária total mínima de 300 horas, as atividades foram divididas em 4 dimensões. São elas: (I) cultural, até 75 horas ou 25\%; (II) extensão, até 75 horas ou 25\%; (III) pesquisa, até 75 horas ou $25 \%$ e (IV) profissional, até 75 horas ou $25 \%$. Neste artigo, abordaremos apenas a dimensão cultural.

Os estudos apresentados nortearão especificamente a dimensão (I) cultural, componente integrante das atividades complementares. Dentre o rol de atividades culturais possíveis para realizar presencialmente e as sugeridas no roteiro virtual, têm-se: visitas a museus, teatros, concertos, feiras e cinemas. $O$ discente cumprirá as atividades complementares em conformidade com o roteiro, que abordará de 0 até 10 horas, desde que atendidos todos os critérios formativos e contínuos de avaliação.

A definição de cultura não é fácil. A cultura aborda interesses multidisciplinares, abarca áreas de estudos como Sociologia, Antropologia, História, Comunicação, Administração, Ciências Contábeis e Economia, entre outras. Cada área de estudo mantém a sua particularidade nos enfoques e nos usos. "Tal realidade concerne ao próprio caráter transversal da cultura, que transcorre diferentes campos da vida cotidiana" Canedo (2009). Frequentemente ouve-se falar em "cultura política", "cultura empresarial", "cultura agrícola", "cultura de células" ... Ao se referir ao termo, cabe ponderar que existem distintos conceitos de cultura, no plural, em voga na contemporaneidade.

Pela definição alemã, cultura é "um conjunto de características artísticas, intelectuais e morais que constituem o patrimônio de uma nação, considerado como adquirido definiti- vamente e fundador de sua unidade". Assim, a cultura está enraizada na história dos mais variados povos. A evolução contempla o fruto da criação do homem. Algumas formas de identificá-la são: na arquitetura, música, cinema, teatro, dança, pintura, artesanato e design, entre tantas outras. $O$ estudo da arte permite uma visão crítica-emancipatória. A cultura erudita é oriunda da escolarização e poucas pessoas têm acesso como, por exemplo: visita a galeria de artes, museus, festivais musicais, espetáculos teatrais, de dança ou cinematográficos, dentre outros Canedo (2009).

Logo, as conexões entre as culturas popular, erudita e de massa compõem a nossa história. É necessário ir além da prática etnocêntrica, porque o reconhecimento da pluralidade cultural é o ato de identificar e compreender as diferenças para o convívio harmônico. Visto o exposto, as relações mediadas pelas Tecnologias Digitais de Informação e Comunicação (TDIC) fazem parte do cotidiano das pessoas, e decorre para o processo de ensino-aprendizagem.

Vale, no entanto, retomar o conceito de competências, que segundo (Fleury \& Fleury, 2001) "é pensado como o conjunto de conhecimentos, habilidades e atitudes que justificam uma alta performance, acreditando-se que os melhores desempenhos estão fundamentados na inteligência e na personalidade das pessoas". Costa (2015) observa que o conceito de competência "CHA" (Conhecimentos, Habilidades e Atitudes) pode ser desmembrado, para ser tratado separadamente, como: Competência Técnica (Conhecimentos e Habilidades) e Competência Comportamental (Atitudes). O termo competência pode ser tratado de diversas maneiras, como destacamos a seguir. A palavra competência é originária do latim, competentia utilizada no século XV na língua francesa como termo jurídico (ABED, 2012). Segundo Fleury \& Fleury (2001), este termo 
é utilizado como sinônimo de pessoa qualificada para realizar determinada tarefa, enquanto o seu sinônimo é utilizado de forma depreciativa, desde o ambiente social ao profissional. As literaturas europeias e americanas abordam discussões que buscam traduzir de forma mais clara o conceito de competência em diversos níveis desde às estratégias organizacionais aos processos de aprendizagem, buscando o desenvolvimento de competências individuais. $\bigcirc$ debate sobre competência iniciou-se em 1973, por meio do paper Testing for Competence rather than Intelligence escrito por McClelland, no qual ele a define como "característica subjacente a uma pessoa que é casualmente relacionada com desempenho superior na realização de uma tarefa ou em determinada situação". Desta razão, o significado da competência difere de aptidão, que diz respeito a talento nato de uma pessoa, o qual pode ser aprimorado e de habilidade, ou seja, a demonstração prática de um talento, enquanto o conhecimento é definido como o saber para desempenhar determinada tarefa. Dentre os conceitos abordados, o enfoque se concentra no contexto da competência sendo um conjunto de conhecimentos, habilidades e atitudes. A partir deste contexto, as competências foram selecionadas e aplicadas inicialmente às Atividades Complementares, a fim de desenvolver, avaliar e certificar.

Assim, questiona-se: como as Atividades Complementares Culturais podem contribuir para desenvolver competências no curso de bacharelado em Ciências Contábeis, na modalidade virtual de aprendizagem?

Para tanto, busca-se demonstrar um recurso que possibilite certificar-se de que as atividades propostas nesse componente curricular possam garantir maior confiabilidade ao desenvolvimento das competências requeridas para uma formação de qualidade aos alunos de bacharelado no Curso de Ciências Contá- beis na modalidade de Educação à Distância.

Objetivo: direcionar e alinhar as atividades complementares culturais nas interseções da matriz de referência de Ciências Contábeis para o desenvolvimento e a avaliação por competências. A relevância da temática surge com a necessidade de direcionar e alinhar a virtualização do curso de bacharelado em Ciências Contábeis assegurando a educação inclusiva, equitativa e de qualidade, bem como promover as oportunidades de aprendizagem com base nas orientações do Ministério de Educação e com enfoque no objetivo 4 da Organização das Nações Unidas no Brasil, que visa aumentar o número de jovens e adultos possuidores de competências relevantes para o trabalho decente ou ao empreendedorismo (ONU, 2017).

Avaliar é um processo amplo e complexo, pois está além do nível individual, também, possui vertentes coletivas e institucionais. As características da avaliação e a sua finalidade ultrapassam os indicadores meritocráticos de classificação dos discentes, docentes, cursos, instituições e órgãos reguladores da educação. A avaliação deve formar e desenvolver o indivíduo, a qual reconfigura o próprio, para a reconstituir o seu contexto social para a construção das competências necessárias ao perfil, o qual a instituição deseja formar. O processo de avaliação deve contribuir com a formação e o desenvolvimento, de maneira a impactar a reconfiguração de cenários sociais e educacionais, para a constituição de alternativas viáveis à construção das competências necessárias ao perfil desejado. Os estudos sobre políticas educacionais ganharam notoriedade na última década, especialmente a avaliação por competências como vertente para a criação de ferramentas, do mesmo modo que o monitoramento da qualidade da educação e da formação e capacitação profissional. Evidencia-se, desse modo, os desafios das pro- 
postas de avaliação por competências, bem como a certificação das mesmas (Lima, Silva \& Paiva, 2010).

\section{Metodologia}

A inquietação buscou novos conhecimentos sobre a temática: avaliar e certificar por meio das competências. Desde o início do primeiro semestre letivo de 2017 foram observadas as estratégias pedagógicas de uma instituição de ensino superior particular localizada na Baixada Santista, mais precisamente na cidade de Santos, estado de São Paulo, Brasil. Para isso, foram analisados e comparados os perfis de egressos dos Projetos Pedagógicos dos Cursos de ciências contábeis com o descrito no Parecer $n^{\circ}$ 67, aprovado pela Câmara Nacional de Educação Superior, localizadas no Distrito Federal do Brasil, em 11 de março de 2003, no qual aborda o Referencial para as Diretrizes Curriculares Nacionais - DCN dos Cursos de Graduação.

Não obstante, analisou-se, também, a Portaria $\mathrm{n}^{\circ} 220$, aprovada em 10 de junho de 2015 pelo presidente do Instituto Nacional de Estudos e Pesquisas Educacionais Anísio Teixeira - Inep abordam, como objetivos em seus primeiros parágrafos: "avaliar o desempenho dos estudantes em relação aos conteúdos programáticos previstos nas diretrizes curriculares, às habilidades e competências", visto isto: "para a atualização permanente e aos conhecimentos sobre a realidade brasileira e mundial, bem como sobre outras áreas do conhecimento".

Nesta investigação foi adotado o paradigma qualitativo embasado em Silva (2010), onde a princípio compreende os fenômenos sociais segundo as perspectivas dos participantes, haja visto os métodos e as técnicas que foram utilizados pela observação dos pesquisadores e análise comparativa documental.

O curso é estruturado em matriz curricular composta por 3.600 horas/aula subdivididas em 8 semestres letivos, cada um contendo 6 disciplinas, incluindo-se os projetos integradores de 1 a 14 e as 4 atividades complementares. Este, oferecido na modalidade a distância, por meio de uma plataforma virtual de aprendizagem, Modular Object Oriented Dynamic Learning Environment.

Neste contexto, surgiu a necessidade de planejar uma matriz de referência educacional como sugestão de método pedagógico integrador que permita a melhor alocação das atividades respeitando as competências para atingir os perfis desejados. Portanto, para este estudo adotou-se uma abordagem qualitativa exploratória sobre a temática - virtualização do ensino superior de Ciências Contábeis: implementação de atividades complementares culturais avaliadas por competências.

Neste artigo evidencia-se as atividades complementares culturais, que foram implementadas por meio de ações formais que visam a melhoria da qualidade de vida e ao desenvolvimento pessoal, profissional, social, emocional e intelectual do discente; tendo como exemplos: filmes, teatros, museus, concertos, artesanatos e livros, entre outros, porque priorizam a interdisciplinaridade, ampliando assim a formação e flexibilização do aprendizado.

O desenvolvimento das atividades complementares foi realizado e avaliado respeitando a matriz de referência do curso para ampliação dos conhecimentos, habilidades e atitudes dos discentes, com o enfoque nas competências de 1 a 5 para atingir os perfis de 1 a 3 , perpassando pelos objetos de aprendizagem.

\section{Resultados}

Na matriz de referência elaborada para o desenvolvimento de competências por meio das atividades científico-culturais, tem-se: na colu- 
na 1 - as competências de 1 a 5; na coluna 2 as descrições das competências e nas colunas 3 a 5 , os perfis $1^{*} ; 2^{* *}$ e $3^{* * *}$, onde são inter-relacionadas as atividades propostas aos discentes, enumeradas de 1.0 a 1.4 , de modo a atingir os diferentes graus de perfis.

*Perfil 1 - Compreender questões científicas, técnicas, sociais, contábeis, econômicas e financeiras em âmbito nacional e internacional e nos diferentes modelos de organização e segmentos econômicos. **Perfil 2 - Demonstrar raciocínio lógico-quantitativo na solução de questões em diferentes cenários. ***Perfil $\mathbf{3}$ - Manifestar capacidade crítico-analítica, inclusive em atividades de apurações, auditorias, perícia, arbitragens e quantificações de informações financeiras, patrimoniais públicas e privadas, para os usuários da informação contábil.

\section{Discussão}

Nossos resultados mostram que a matriz de referência educacional é uma proposta prática de integração entre perfis e competên- cias profissionais. Treinamento baseado em competência é um critério de organização do ensino que contrapõe ao modelo tradicional, baseado numa aprendizagem fragmentária Bergsmann et al., (2015), Marín (2017), Bacich \& Moran (2018), Serrano et al., (2018) \& Costa et al. (2018). Desse modo, a matriz de referência educacional é apresentada como metodologia ativa, pois direciona ações para que o discente desenvolva competências, e assim, atingir o perfil profissional desejado Craft et al., (2016), Ellis \& Goodyear (2016). Então o projeto pedagógico do curso assim organizado, equilibra a aprendizagem individualizada com a colaborativa, bem como redesenha os espaços físicos e virtuais, com apoio das tecnologias digitais Moran (2015), Moran \& Bacich (2018).

A consequência da virtualização impacta diretamente nos contextos: econômico, social e educacional, devido a tecnologia estar cada vez mais presente nas relações da sociedade Serrano et al., (2018). Pesquisadores apontam efeitos específicos da internet, que influenciam ambientes virtuais e linguagens no cotidiano das pessoas. A relação docente-discen-

Tabela 1 - Modelo de matriz de referência para o desenvolvimento do ensino-aprendizagem para o curso de ciências contábeis oferecido na modalidade virtual

\begin{tabular}{|c|c|c|c|c|}
\hline Competência & Descrição & Perfil 1 & Perfil 2 & Perfil 3 \\
\hline & & • & ** & $\ldots$ \\
\hline 1 Terminologia & $\begin{array}{l}\text { Exercer as funçōes contábeis adequadamente utilizando a terminologia e } \\
\text { linguagem da ciência contábil. }\end{array}$ & $\begin{array}{l}1.0 \\
\text { e } 1.2\end{array}$ & & \\
\hline 2 Apuraçăo & $\begin{array}{l}\text { Praticar atividades de apuraç̋es, auditorias, pericias, arbitragens e } \\
\text { quantificaçōes de informaçōes financeiras, patrimoniais públicas e privadas. }\end{array}$ & & & 1.3 \\
\hline 3 Compreensẩo & $\begin{array}{l}\text { Interpretar a normatizaçăo e pronunciamentos inerentes à contabilidade, gerando } \\
\text { informaçóes para o processo decisório, bem como identificar as questōes éticas } \\
\text { profissionais e os impactos da responsabilidade socioambiental nas } \\
\text { organizaçōes. }\end{array}$ & 1.4 & 1.4 & 1.4 \\
\hline 4 Construção & $\begin{array}{l}\text { Construir pareceres e relatórios que contribuam para o desempenho da gestâo } \\
\text { dos usuários da informaçăo contábil, quaisquer que sejam os modelos } \\
\text { organizacionais. }\end{array}$ & $1 . .4$ & & \\
\hline 5 Análise & $\begin{array}{l}\text { Organizar informaçōes aos usuários para subsidiar o desenvolvimento } \\
\text { tecnológico e sistemas de informaçôes contábeis. }\end{array}$ & 1.0 & & \\
\hline
\end{tabular}


te é mediada por tecnologias em proporção crescente, além das formas de avaliação de desempenho baseadas em dados. Assim, o cotidiano é controlado por algoritmos e sistemas computacionais e não somente de relações por meio de normas sociais e interações mediadas por linguagens naturais. Costa et al. (2018).

Fundamentadas na Portaria Inep $n^{\circ} 220$, de 10 de junho de 2015 , foram direcionadas as propostas das atividades levando em consideração o desenvolvimento das competências discentes, tais que as mesmas foram alinhadas nas interseções contidas na Tabela 1. Dentre as dimensões das atividades culturais possíveis, o relato de experiência foi sugerido: portanto, que o aluno conceitue a cultura popular, cultura erudita e cultura de massa. Assim, ele deve analisar como as culturas influenciam o cotidiano da sociedade na qual o mesmo está inserido. Neste sentido, ao elaborar a Atividade 1.0, pretende-se que o discente desenvolva a competência 1 - terminologia, pois exercerá a função adequadamente, utilizando-se dos termos próprios sociais, bem como atingir o Perfil 1, porque deverá compreender questões sociais, no âmbito nacional e internacional e nos diferentes modelos e segmentos. Proposta de Atividade 1.2: elaborar um relato de experiência, com base em uma ou mais visitas a museus, teatros, festivais e cinemas, dentre outros. O desenvolvimento compete em trabalhar a Competência 1 em prol de reforçar o alcance também do Perfil 1. Enquanto a Atividade 1.3 abarca a leitura do capítulo 3 - a singular narrativa da aventura dos 35 camelos que deveriam ser repartidos por 3 árabes. Beremiz Samir efetua a divisão que parecia impossível, contentando plenamente os 3 querelantes, com o enfoque no lucro obtido com a transação (Tahan, 2012). As competências esperadas são: a terminologia e a apuração, pela prática de apurações e quantificações de informações financeiras, como a divisão de um lote de camelos herdados aos irmãos, além de prevalecer a vontade do pai. $O$ enfoque está no Perfil 3, pois manifesta a capacidade crítica-analítica da atividade de apuração, por meio da elaboração de um texto on-line descrevendo a percepção frente ao conto, levando em consideração a função do contador na contemporaneidade.

Ao assistir o videoaula de matemática e música, como proposta 1.4 é possível que o discente discorra sobre a importância da matemática e da música para o profissional contábil, com o objetivo de reforçar a compreensão dos termos abordados. Estudiosos inferem que o curso de Ciências Contábeis oferecido na modalidade virtual, no Rio de Janeiro, obteve resultados significativos se comparado ao presencial Lima, Silva \& Paiva (2010).

\section{Considerações finais}

Este artigo procurou demonstrar uma proposta para o direcionamento e alinhamento das atividades complementares culturais nas interseções da matriz de referência do curso de bacharelado em Ciências Contábeis. Sendo assim, entende-se possível incentivar o desenvolvimento de competências via plataforma on-line, com o recurso as atividades complementares culturais. Observa-se, no mapeamento das atividades, que as interseções podem corroborar com a avaliação contínua e formativa discente. Haja vista que as atividades complementares culturais podem ir além do estabelecido na legislação vigente, porque permite desenvolver as capacidades cognitivas socioculturais dos discentes em busca de uma aprendizagem significativa. A matriz de referência contribui para direcionar e alinhar as competências com o objetivo de alcançar o perfil do egresso, ou seja, nas interseções são mapeadas as atividades, as quais possibilitam uma análise mais detalhada dessa correlação. 


\section{Referencias}

ABED, A. B. (2012). Competências para educação a distância: Matrizes e referenciais teóricos. ABED, Associação Brasileira de Educação a Distância - 85.

Bacich, L., Moran, J. (2018). Active methodologies for an innovative education: a theoreticalpractical approach. Porto Alegre: Penso

Bergsmann, E., Schultes, M. T., Winter, P., Schober, B. Spiel, C. (2015). Evaluation of competencebased teaching in higher education: From theory to practice. Evaluation and Program Planning.

Canedo, D. (2009). Cultura é o quê? - Reflexões sobre o conceito de cultura e a atuação dos poderes públicos. V ENECULT - Encontro de Estudos Multidisciplinares em Cultura. http://www.cult.ufba.br/enecult2009/19353.pdf . (Acesso em: 02 fev. 2019)

Costa, C. C. S. (2015) Recrutamento e seleção por competências: dificuldades e benefícios. In: XI CONGRESSO NACIONAL DE EXCELÊNCIA EM GESTÃO

Costa, D. A. S., Silva, R. F., Lima, V. V., Ribeiro, E. C. O. (2018). National curriculum guidelines of the health professions 2001-2004: analysis in the light of curriculum development theories. In: Interface communication, health and education.

Craft, A., Horin, O. B., Sotiriou, M., Stergiopoulos, P., Sotiriou, S., Hennessy, S., Dobrivoje, E.L., (2016). CREATIT: Implementing creative strategies into science teaching. In New developments in science and technology education

Ellis, R. A., Goodyear, P. (2016). Models of learning space: integrating research on space, place and learning in higher education. In: Review of Education

Fleury, M. T. L., \& Fleury, A. (2001). Construindo o conceito de competência. Revista de administração contemporânea, 5 (SPE), 183 -196
Inep, Sinopses 2007 e 2015. www.inep.gov.br (Acesso: 10 mar. 2018)

Lima, J. Silva, C., \& Paiva, C. (2010). Autonomia em educação a distância: Relatos a partir da prática de tutoria na disciplina fundamentos psicológicos da educação em dois cursos de licenciatura da ufbvirtual. http://www.abed.org.br/congresso2010/ cd/352010000839.pdf. (Acesso em: 17 jul. 2017)

Marín, Y. (2017). The teaching of pedagogical experiences. In: Revista Góndola biodiversity: trends and challenges in, Enseñanza y Aprendizaje de las Ciência.

Moran, J. M. (2018). Metodologias ativas e modelos híbridos na educação. http://www2.eca.usp.br/moran/ (Acesso: 26 mar. 2018)

Noveli, M., Albertin, A. L. (2018) Um estudo da virtualização de processos: o uso de mundos virtuais com foco em ensino-aprendizagem. Revista Brasileira de Educação, v. 22, n’. 7. http://dx.doi.org/10.1590/ S1413-24782017227151 (Acesso: 15 mar. 2018)

ONU. (22 de novembro de 2017). Nações Unidas no Brasil. Fonte: ONUBR - Nações Unidas no Brasil: https:// nacoesunidas.org/pos2015/agenda2030/ (Acesso em: 17 jul. 2017)

Semesp. Mapa do Ensino Superior (2018). http://www. semesp.org.br/publicacoes/revista-ensino-superior/ (Acesso: 09 mar. 2018)

Serrano R. R., Amor, M. I., Guzman, C. Á., Guerrero-Casado, J., (2018). Validation of an Instrument to Evaluate the Development of University Teaching Competences in Ecuador. Journal of Hispanic Higher Education.

Silva, A. C. (2010). Metodologia da Pesquisa Aplicada à Contabilidade. Orientações de Estudos, Projetos, Artigos, Relatórios, Monografias, Dissertações, Teses. São Paulo, São Paulo, Brasil: Atlas. 
Tahan, M. (2012). O homem que calculava. $3^{a}$ ed. Bestbolso: Rio de Janeiro

Toukoumidis, A. T., Rodriguéz, L. M. R, Rodriguéz, A. P. (2018) Ludificación y sus posibilidades en el entorno de blended learning: revision documental Gamification and its possibilities in the blended learning environment: literature review. RIED. Revista Iberoamericana de Educación a Distancia, v. 21, n. 1 pág. 95-111,. http://revistas.uned.es/index.php/ried/ article/view/18792. (Acesso: 25 mar. 2018)

2018, Vol. 12(23) 47-56 @ The Author(s) 2018 Reprints and permission: www.americana.edu.co 